\title{
PURWARUPA SISTEM INFORMASI KADASTER 3D BERBASIS WEB (STUDI KASUS : RUMAH SUSUN PENJARINGAN SARI, KOTA SURABAYA)
}

\author{
Andy Laksmana Darmawan, Yanto Budisusanto \\ Program Studi Teknik Geomatika, FTSP, ITS-Sukolilo, Surabaya, 60111 \\ Email : andy.laksmana.darmawan10@mhs.geodesy.its.ac.id
}

\begin{abstract}
Abstrak
Kebutuhan informasi pertanahan 3D saat ini sangat dibutuhkan masyarakat seiring dengan perkembangan pertumbuhan pembangunan dari pembangunan horizontal ke arah pembangunan vertikal. Salah satu informasi kadaster 3D yang perlu dikembangkan adalah mengenai Rumah Susun Sederhana Sewa (Rusunawa). Dalam penelitian ini Rusunawa yang dijadikan sebagai studi kasus penelitian adalah Rumah Susun Penjaringan Sari Surabaya yang dikelola oleh Pemerintah Kota Surabaya.

Untuk menghasilkan informasi kadaster 3D dari Rumah Susun Penjaringan Sari Surabaya dibutuhkan data denah gedung beserta data penghuni Rumah Susun Penjaringan Sari Surabaya. Data-data tersebut digunakan untuk membuat basis data 3D. Basis data 3D dibuat dengan menggunakan software PostgreSQL+PostGIS dan selanjutnya diintegrasikan dengan sistem informasi sehingga dapat dihasilkan visualisasi dari purwarupa sistem informasi kadaster 3D berbasis web.

Penelitian ini menghasilkan produk berupa purwarupa atau prototype berupa web informasi kadaster 3D yang dapat mengakomodasi pendaftaran sewa menyewa dari Rumah Susun Penjaringan Sari dengan model dinamis sehingga data-data yang ada dapat diupdate ketika mengalami perubahan data. Dari penelitian ini diharapkan dapat dijadikan bahan pertimbangan untuk mengaplikasikan sistem informasi kadaster 3D di Indonesia secara online.
\end{abstract}

Kata Kunci : Kadaster 3D, basis data 3D, sistem informasi, Web

\section{PENDAHULUAN}

\section{Latar Belakang}

Informasi pertanahan saat ini sangat dibutuhkan oleh semua lapisan masyarakat, Ketersediaan informasi pertanahan ini dibuat dalam suatu sistem yang disebut Sistem Informasi Pertanahan. Sistem Informasi Pertanahan merupakan suatu komponen yang terdiri dari perangkat keras, perangkat lunak, data persil (kadaster) lahan dan sumber daya manusia yang bekerja sama secara efektif untuk memasukan, menyimpan, memperbaiki, memperbaharui, mengelola, memanipulasi, mengintegrasikan, menganalisis dan menampilkan data dalam suatu informasi yang berisi keterangan mengenai persil lahan (status kepemilikan, luasan, penggunaan lahan, zoning site) (Yudono A, 2011).

Perkembangan sistem informasi pertanahan di Indonesia sangat berhubungan dengan kegiatan pembangunan di Indonesia yang telah berubah dari arah horizontal kearah vertikal sehingga data pertanahan yang dibutuhkan menjadi lebih kompleks. Oleh karena itu, dibutuhkan suatu pendekatan Kadaster 3 Dimensi agar dapat mendefinisikan data pertanahan dari suatu bangunan vertikal yang biasa disebut dengan Kadaster 3D. Kadaster 3D merupakan sistem kadaster yang melakukan pendaftaran dan memberikan gambaran pada hak atau kewenangan serta batasan-batasan, tidak hanya pada persil tanah, tetapi pada properti 3D (Stoter, 2004).

Pendekatan Kadaster 3D didasari oleh UndangUndang No. 20 tahun 2011 mengenai Rumah Susun sehingga Kadaster 3D semakin dibutuhkan. Rumah susun adalah bangunan gedung bertingkat yang dibangun dalam suatu lingkungan yang terbagi dalam bagian-bagian yang distrukturkan secara fungsional, baik dalam arah horizontal maupun vertikal dan merupakan satuan-satuan yang masing-masing dapat dimiliki dan digunakan secara terpisah, terutama untuk tempat hunian yang dilengkapi dengan bagian bersama, benda bersama, dan tanah bersama. Salah satu informasi Kadaster 3D yang perlu dikembangkan adalah 
mengenai Rumah Susun Hak Sewa (Rusunawa) agar memudahkan akses bagi masyarakat untuk mendapatkan informasi serta melakukan pendaftaran untuk menjadi penghuni Rusunawa tersebut. Oleh karena itu, penelitian ini bertujuan untuk membangun purwarupa sistem informasi Kadaster 3D berbasis web agar dapat diaplikasikan di Indonesia.

\section{Perumusan Masalah}

Perumusan masalah yang dibahas pada penelitian Tugas Akhir ini adalah sebagai berikut:

1. Bagaimana membuat model 3 Dimensi Rumah Susun Penjaringan Sari Surabaya dengan menggunakan AutoCAD CIVIL 3D 2012 Metric?

2. Bagaimana pemodelan Database Management System dan menghubungkannya dengan data spasial?

3. Bagaimana membuat web design dari sistem informasi kadaster 3D?

\section{METODOLOGI PENELITIAN}

\section{Lokasi Penelitian}

Lokasi Penelitian berada di Rumah Susun Penjaringan Sari, Surabaya. Secara geografis Rusun Penjaringan Sari terletak pada 7o19'11,05"-112047'03,28 dan 7o19'12,37"$112047^{\prime} 03,21^{\prime \prime}$.

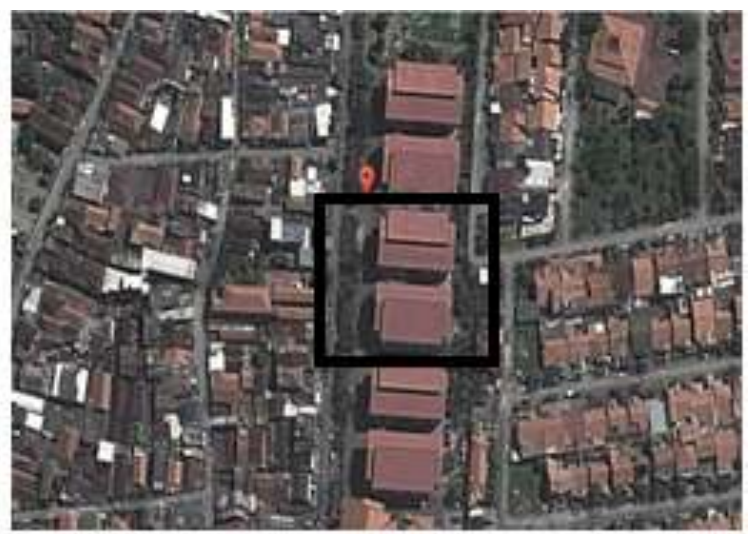

$=$ Lokasi Penelitian

Gambar 1. Lokasi Penelitian

\section{Data Dan Peralatan}

- Data

Data yang digunakan dalam penelitian tugas akhir ini adalah:

1. Denah gedung Rumah Susun Penjaringan Sari Surabaya yang didapat dari Dinas Pekerjaan Umum Surabaya.

2. Data penduduk tiap ruang Rumah Susun Penjaringan Sari Surabaya yang didapat dari UPT Rumah Susun Penjaringan Sari Surabaya.

\section{- Peralatan}

Peralatan yang digunakan dalam penelitian ini adalah Laptop, GPS Navigasi, AutoCAD Civil 3D 2012 Metric, PostgreSQL, XAMPP, Dreamweaver 8 dan Microsoft Office 2013

\section{Tahapan Penelitian}

Diagram Alir penelitian pada penelitian ini dibagi menjadi 2 tahapan, yaitu:

Tahapan Pengolahan Data Spasial

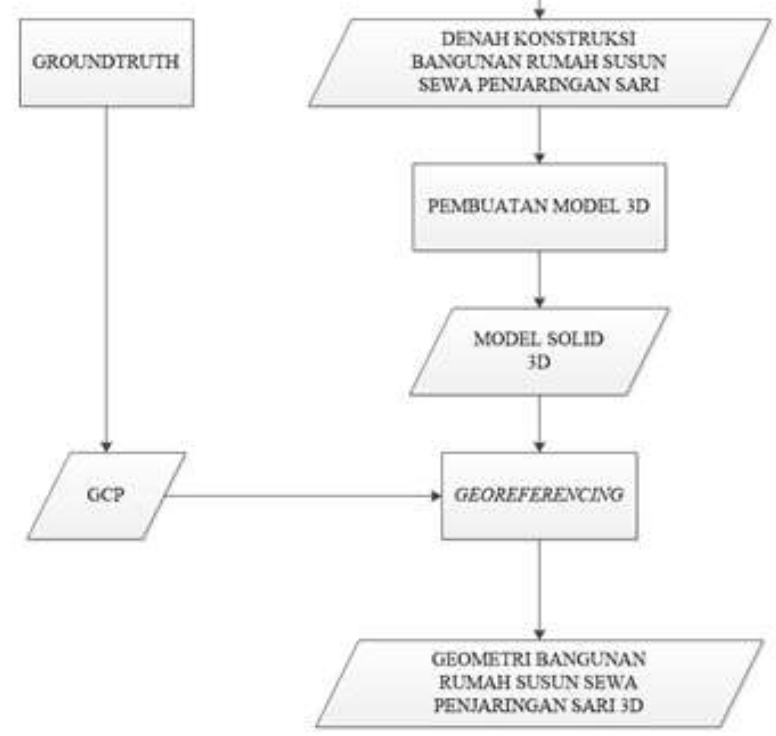

Gambar 2. Diagram Alir Tahapan Pengolahan Data Spasial

Berikut adalah penjelasan diagram alir tahapan pengolahan data spasial:

1. Denah Konstruksi Bangunan Rumah Susun Penjaringan Sari

Denah konstruksi yang digunakan berupa peta dalam format hardcopy dengan skala 1:100. 
Selanjutnya dilakukan konversi data dari format hardcopy menjadi format digital melalui proses digitasi dengan menggunakan software AutoCAD Civil 3D 2012 Metric.

\section{Pembuatan Model 3D}

Pada tahap ini dilakukan proses pemodelan tiga dimensi (3D) berdasarkan data elevasi dan data tinggi yang terdapat pada denah konstruksi bangunan Rumah Susun Penjaringan Sari, sehingga didapatkan model solid 3D dari bangunan tersebut.

\section{Georeferencing}

Pada tahap ini dilakukan proses pendefinisan posisi koordinat pada model 3D dari Rumah Susun Penjaringan Sari Surabaya dengan menggunakan titik GCP (Ground Control Point) yang didapat dari hasil Groundtruth, sehingga bangunan 3D dari Rumah Susun Penjaringan Sari tersebut memiliki posisi dalam sistem koordinat UTM (Universal Transverse Mercator). Selanjutnya dari proses georeferencing ini dihasilkan geometri bangunan Rumah Susun Penjaringan Sari 3D.

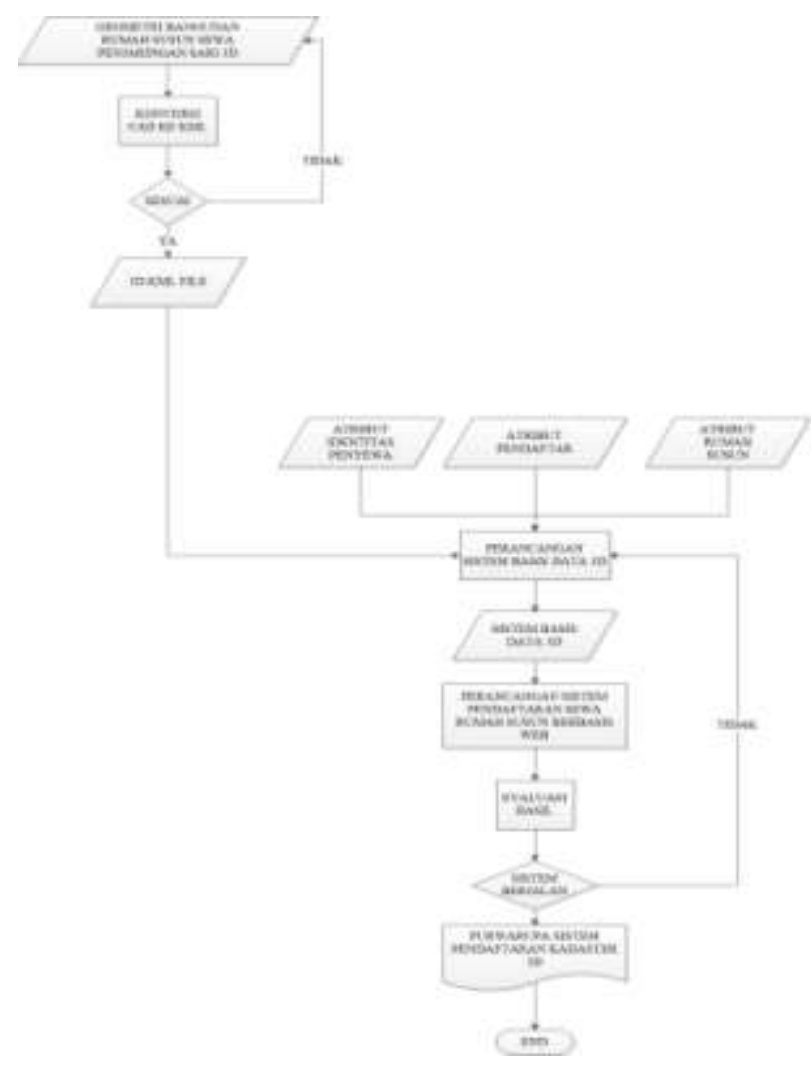

Gambar 3. Diagram Alir Pengolahan Data Atribut
Berikut adalah penjelasan diagram alir tahapan pengolahan data atribut:

1. Konversi $C A D$ ke $K M L$

Proses konversi ini dilakukan untuk menampilkan objek ruang $3 \mathrm{D}$ yang telah dibuat di AutoCAD Civil 3D 2012 Metric ke dalam Google Earth. Apabila file yang dikonversi ketika ditampilkan dalam Google Earth membentuk ruang 3D maka dapat dikatakan bahwa proses konversi berhasil dilakukan. Namun, apabila file yang dikonversi tidak membentuk ruang 3D ketika ditampilkan dalam Google Earth maka konversi harus diulang.

2. Perancangan Sistem Basis Data 3D

Pada tahap ini dilakukan perancangan sistem basis data 3D yaitu menghubungkan atau membentuk query dari setiap data tabel yang ada di dalam PostgreSQL.

3. Perancangan Sistem Pendaftaran Sewa Rumah Susun Penjaringan Sari

4. Pada proses ini dilakukan pembuatan sistem informasi pendaftaran sewa rumah susun Penjaringan Sari berbasis web dengan menggunakan basis data 3D sebagai server data yang nantinya akan diakses dan pembuatan tampilan visualisasi web dari sistem informasi pendaftaran hak sewa secara online.

\section{HASIL DAN PEMBAHASAN \\ 3D Model}

Model solid 3D dibuat dari data model 2D dengan memakai tool extrusion yang dimiliki oleh AutoCAD Civil 3D 2012 Metric dan memasukkan data elevasi dari tiap persil.

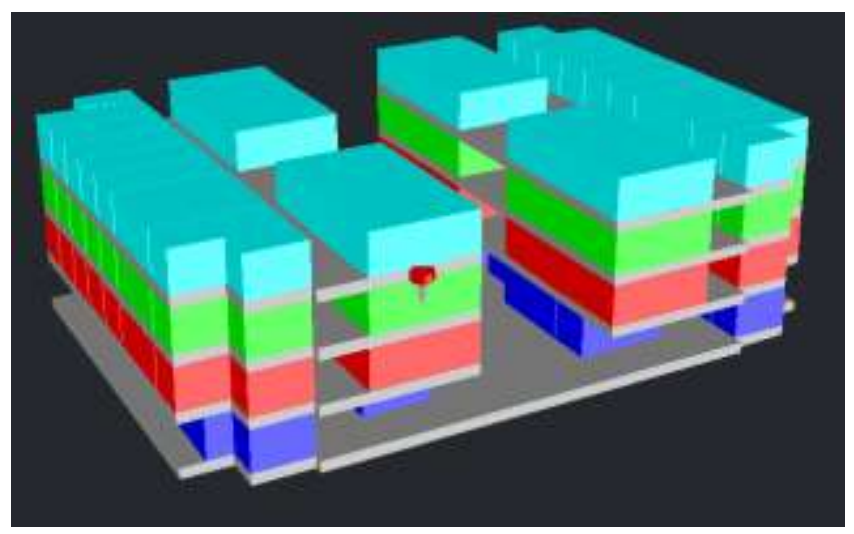

Gambar 4. Model 3D Rumah Susun Penjaringan Sari 
a. Perancangan Basis Data 3D

Perancangan Basis Data 3D dilakukan dengan membuat Entity Relationship Diagram (ERD) yang menunjukkan hubungan antar atribut yang berhubungan dengan data spasial.

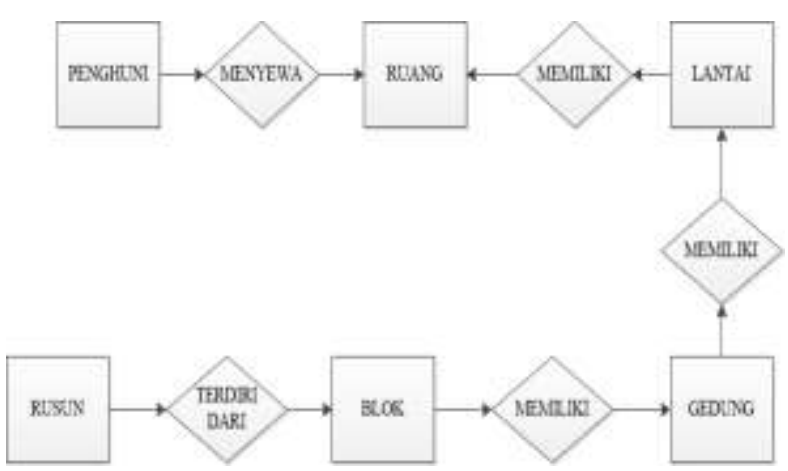

Gambar 5. Entity Relationship Diagram

b. Visualisasi Purwarupa Sistem Infomasi Kadaster 3D Berbasis Web

Visualisasi purwarupa sistem informasi kadaster 3D dibuat dengan menggunakan software Macromedia Dreamweaver 8 sehingga menghasilkan desain seperti berikut:

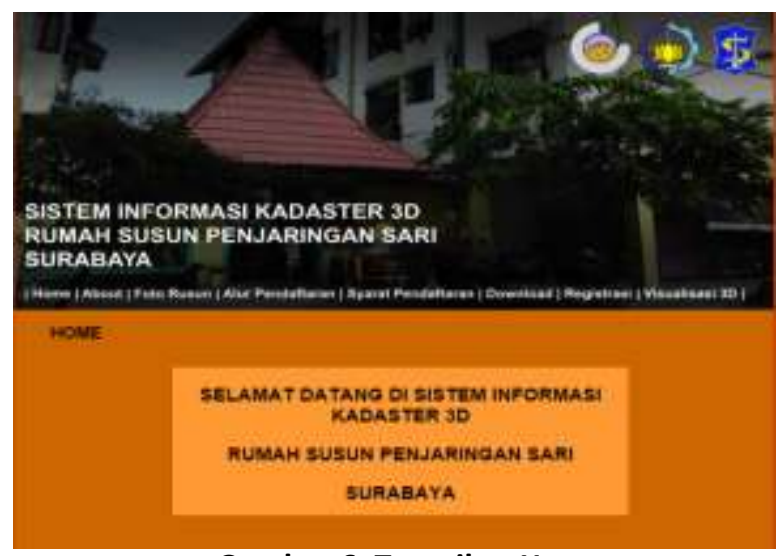

Gambar 6. Tampilan Home

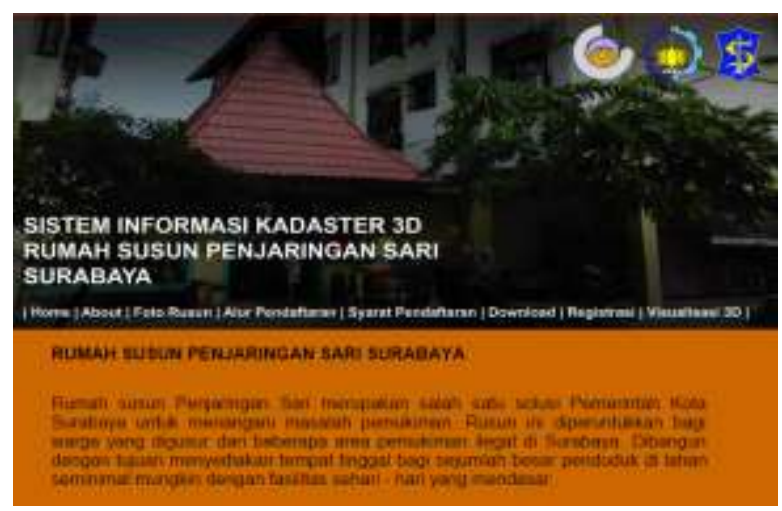

Gambar 7. Tampilan About

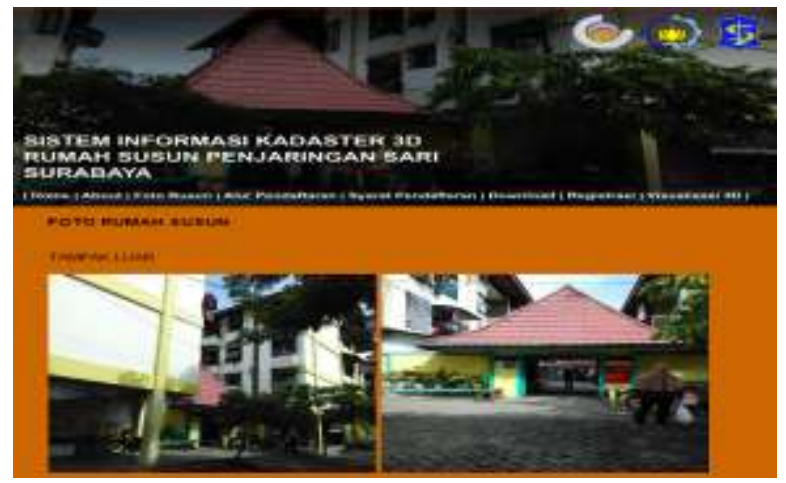

Gambar 8. Tampilan Foto Rusun

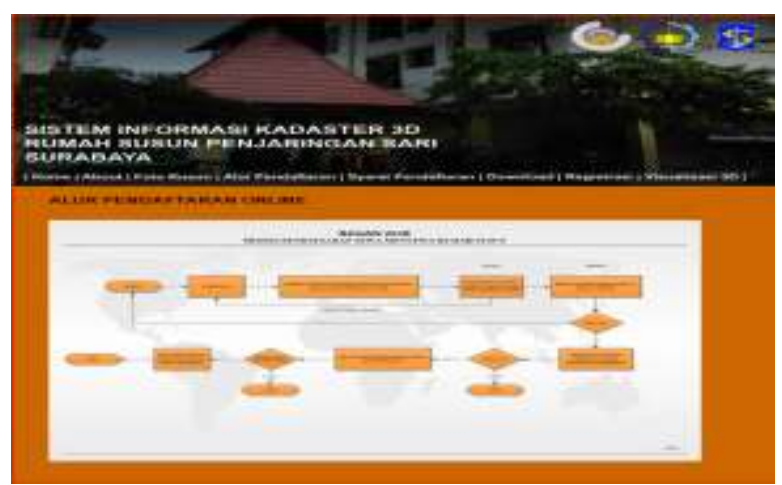

Gambar 9. Tampilan Alur Pendaftaran

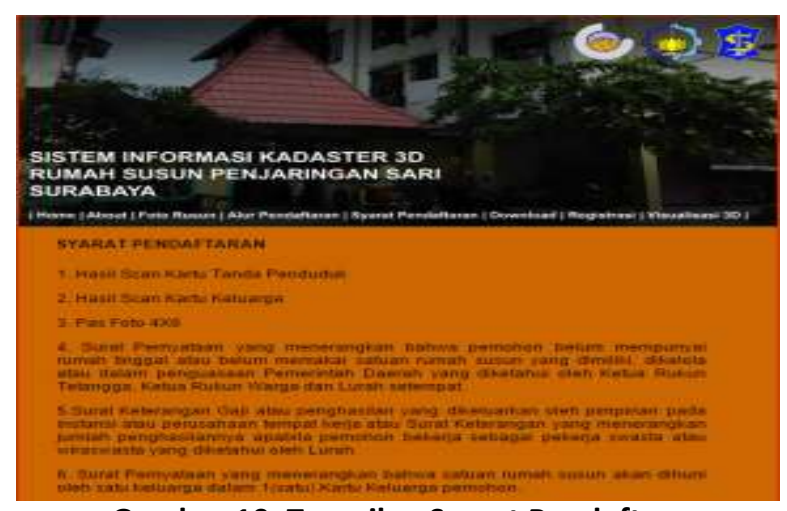

Gambar 10. Tampilan Syarat Pendaftaran

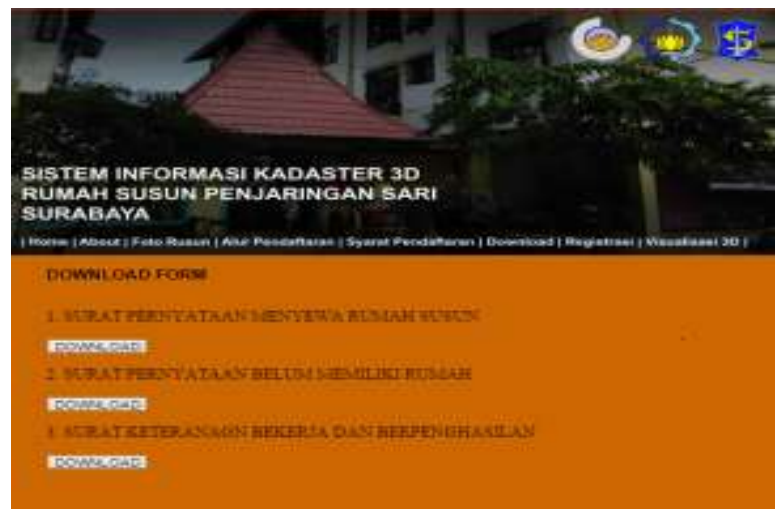

Gambar 11. Tampilan Download 


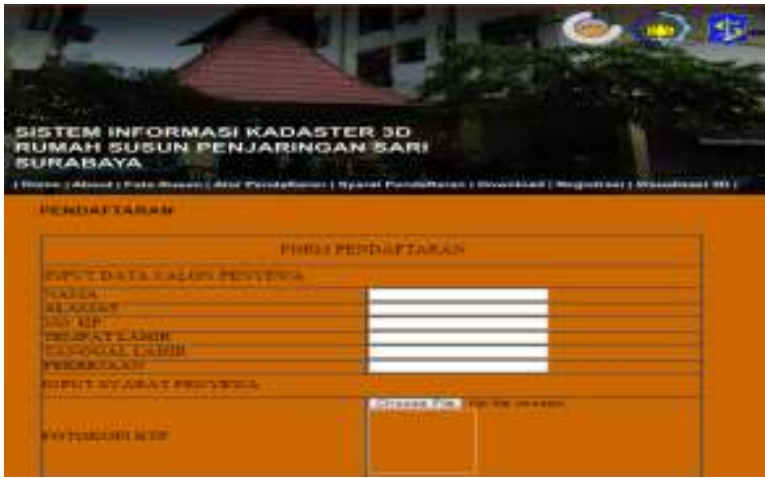

Gambar 12. Tampilan Registrasi

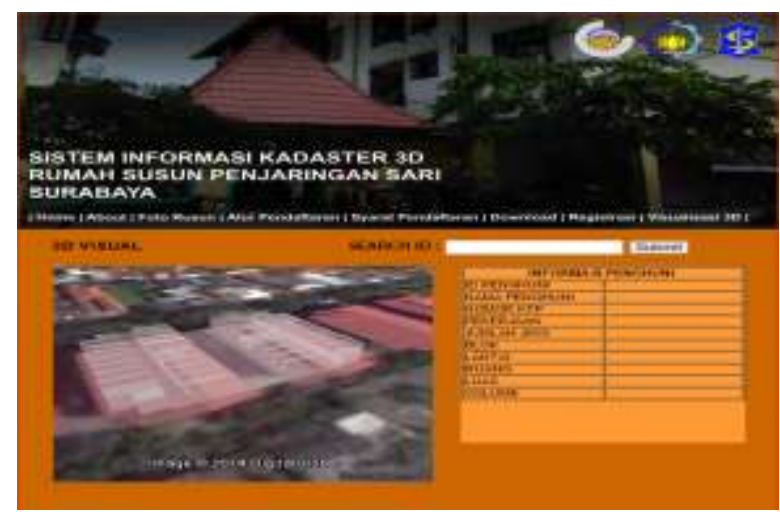

Gambar 13. Tampilan Visualisasi 3D

Dari hasil diatas dapat dilakukan pembahasan sebagai berikut:

a. Model Bangunan 3D

Model bangunan 3D dibuat menggunakan software AutoCAD Civil 3D 2012 Metric dengan memasukan data ukuran persil ruangan dan elevasinya. Pemodelan dibuat dari data denah ruangan yang dirancang oleh dinas PU (Pekerjaan Umum) dalam bentuk hardcopy, kemudian data tersebut dikonversikan dalam bentuk digital dua dimensi (2D) menggunakan AutoCAD Civil 3D 2012 Metric. Gambar di bawah ini merupakan salah satu contoh tampilan konversi gambar dari peta ke dalam bentuk digital:

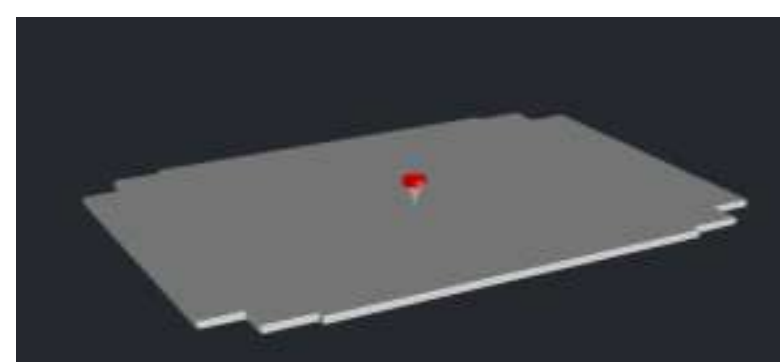

Gambar 14.Contoh Tampilan Konversi Digital
Untuk memberikan koordinat pada hasil konversi gambar digital tersebut dilakukan proses georeference, yaitu proses memberi referensi spasial tertentu pada objek berupa raster atau image yang belum mempunyai acuan sistem koordinat. Dalam penelitian ini proses georeference dilakukan dengan memberikan koordinat berdasarkan data koordinat hasil pengukuran GPS Navigasi di lapangan. Sistem koordinat yang digunakan adalah sistem koordinat UTM (Universal Transverse Mercator) zona $49 \mathrm{~S}$ dan datum WGS (World Geodetic System) 1984. Kemudian dilakukan pendefinisian koordinat menggunakan software AutoCAD Civil 3D 2012 Metric. Pendefinisian tersebut dilakukan pada model 3D yang dibuat agar dapat ditampilkan di Google Earth dalam bentuk file $\mathrm{KML}$ yang menyimpan objek ruang 3D tersebut.

Perubahan model 2D menjadi model 3D dilakukan menggunakan tools Extrusion yang dimiliki oleh AutoCAD Civil 3D 2012 Metric dengan memasukkan tinggi yang dibutuhkan dan elevasi tiap lantai dari gedung rumah susun Penjaringan Sari Surabaya seperti pada gambar berikut ini:

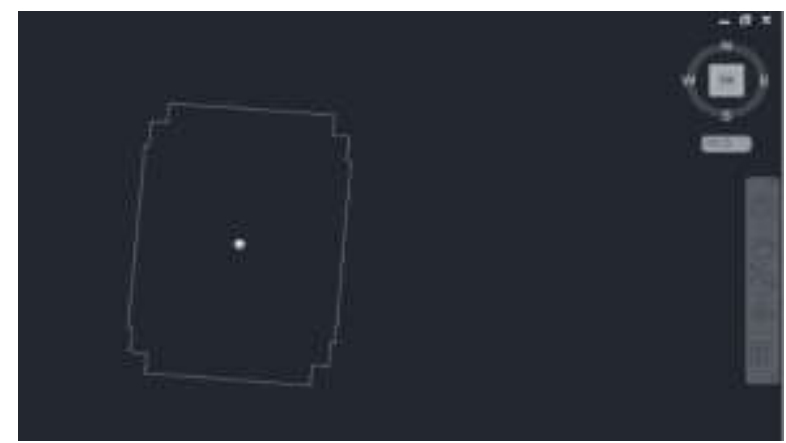

Gambar 15.Tampilan 3D Hasil Ekstrusi

b. Model Database Management System Berbasis 3D

Pembuatan model Database Management System berbasis 3D diawali dengan konversi model bangunan 3D dalam fomat CAD menjadi format KML. Format KML ini dapat menyimpan data objek ruang 3D beserta koordinatnya dan ditampilkan dengan menggunakan Google Earth. Konversi KML tersebut dilakukan 
dengan menggunakan tool Publish KML yang dimiliki AutoCAD Civil 3D 2012 Metric.

Objek-objek yang telah mengalami konversi ke dalam format KML di simpan di dalam satu folder KML yang akan digabungkan dengan data atribut ketika file tersebut dipanggil sehingga membentuk suatu basis data 3D.

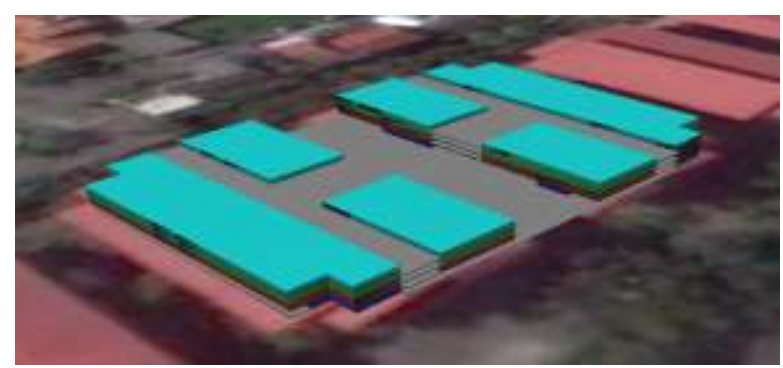

Gambar 16. Tampilan Hasil KML

c. Visualisasi Purwarupa Sistem Informasi Kadaster 3D Berbasis Web

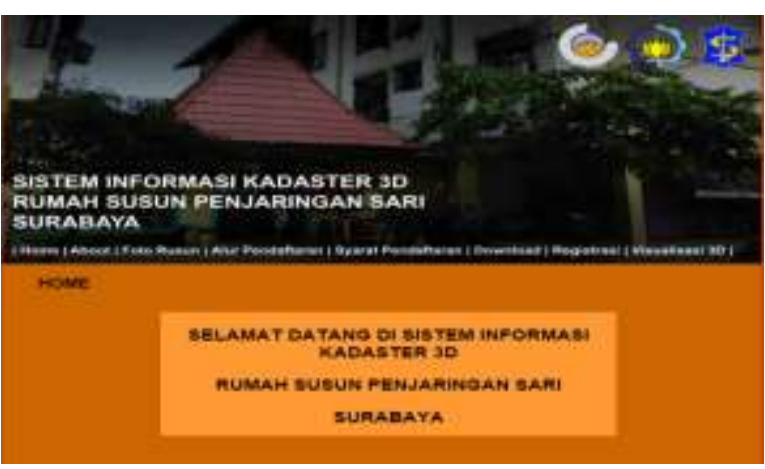

Gambar 18. Tampilan halaman Home

Secara umum, tampilan Home merupakan tampilan awal yang muncul saat user sedang mengakses halaman web. pada tampilan tersebut terdapat ucapan "Selamat Datang di Web Kadaster 3D Rumah Susun Penjaringan Sari" yang ditujukan untuk menyambut user yang membuka halaman halaman tersebut, kemudian terdapat header yang dapat digunakan untuk mengakses halaman About, Foto Rusun, Alur Pendaftaran, Syarat Pendaftaran, Download, Registrasi dan Visualisasi 3D.

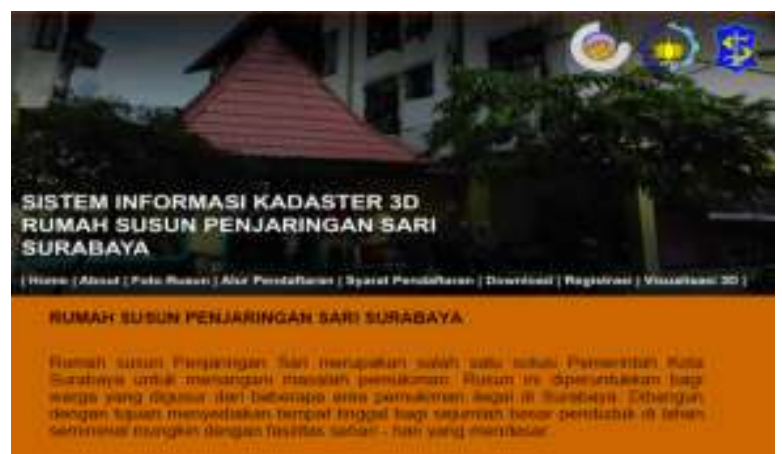

Gambar 19. Tampilan Halaman About

Tampilan halaman About merupakan tampilan yang menampilkan penjelasan singkat mengenai Rumah Susun Penjaringan Sari Surabaya untuk memberikan informasi awal kepada user mengenai Rusun tersebut.

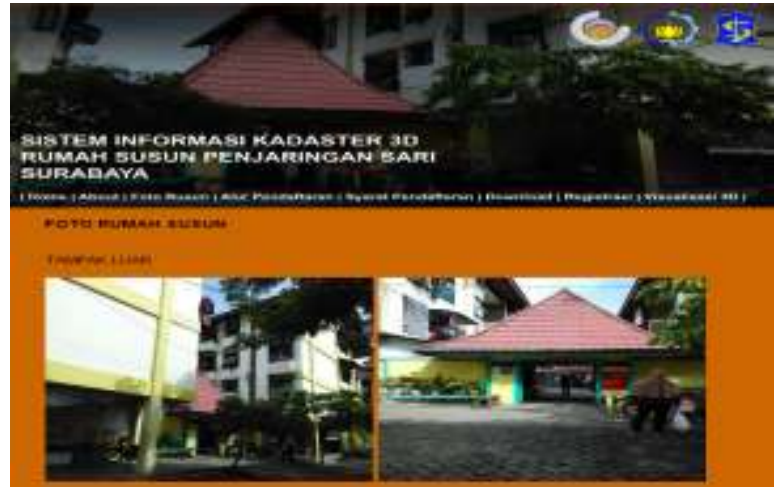

Gambar 20. Tampilan Halaman Foto Rusun

Halaman Foto Rusun merupakan halaman yang disediakan untuk memberikan informasi kepada user yang membuka halaman tersebut mengenai kondisi dari Rumah Susun Penjaringan Sari Surabaya yang dibuktikan dengan foto yang diambil secara langsung di lapangan. Foto-foto tersebut dapat memberikan gambaran kepada user bagaimana kondisi Rumah Susun Penjaringan Sari dari tampak luar, tampak dalam maupun contoh ruangan yang disewakan. 


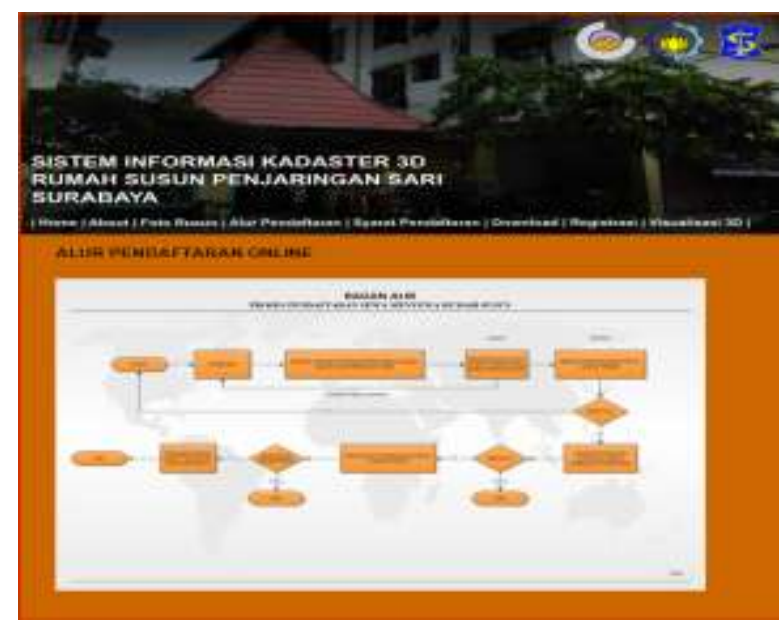

Gambar 21. Tampilan Halaman Alur Pendaftaran

Halaman Alur Pendaftaran merupakan halaman yang dibuat dengan tujuan untuk memberikan informasi kepada user yang membuka halaman ini mengenai bagan alur pendaftaran sewa menyewa beserta syarat-syarat yang dibutuhkan untuk mengajukan permohonan sewa menyewa satuan rumah susun Penjaringan Sari sehingga user dapat mengetahui alur dalam mengajukan permohonan beserta syarat-syaratnya.

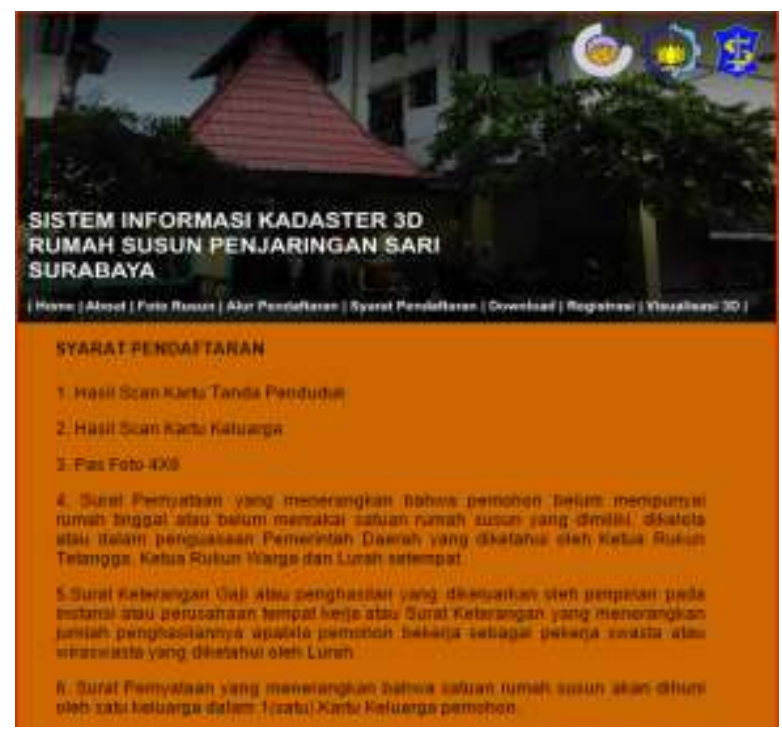

Gambar 22. Tampilan Halaman Syarat Pendaftaran

Halaman Syarat Pendaftaran menampilkan syaratsyarat yang harus dipenuhi oleh calon penghuni Rumah Susun Penjaringan Sari Surabaya secara online. Syarat-syarat tersebut diperoleh berdasarkan Peraturan Walikota Nomor 30 Tahun 2013 mengenai Pelayanan di Bidang Pemkaian Rumah Susun.

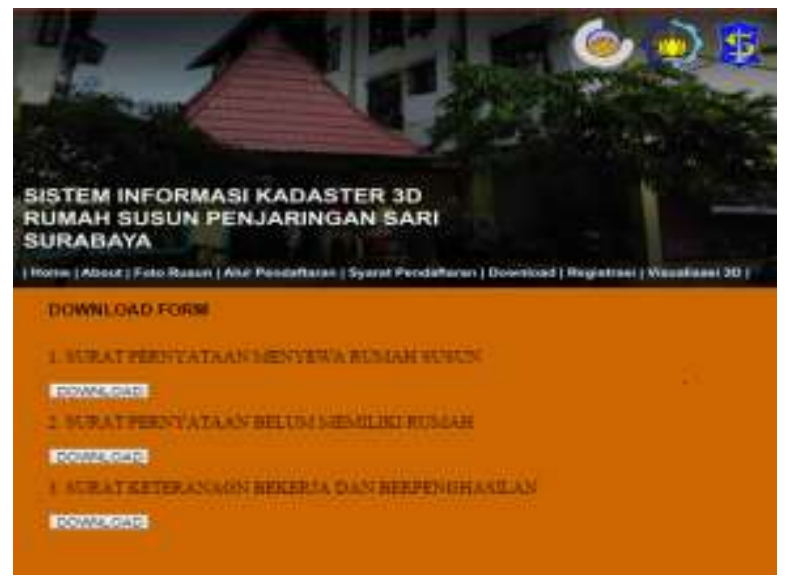

Gambar 23. Tampilan Halaman Download

Halaman Download menampilkan form-form syarat yang harus di download bagi calon penghuni. Halaman ini di buat agar memudahkan calon penghuni untuk mendapatkan syarat-syarat tanpa harus mendatangi Dinas Pengelolaan Bangunan dan Tanah Surabaya untuk mengambil berkas-berkas tersebut.

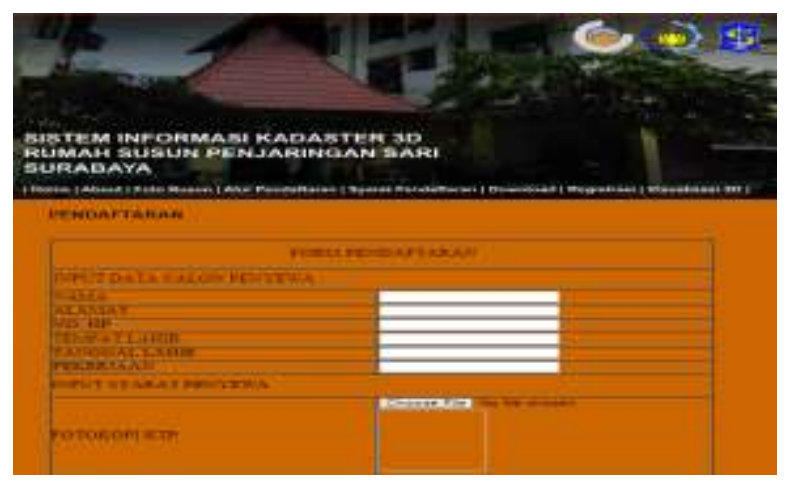

Gambar 24. Tampilan Halaman Registrasi

Tampilan halaman Registerasi disediakan untuk calon penghuni yang ingin mendaftarkan diri secara online dengan memasukkan biodata diri dan mengupload syarat-syarat yang telah ditentukan, kemudian setelah melengkapi biodata diri beserta syarat-syaratna, user dapat mengirimkan data tersebut dengan mengklik tombol "Submit" yang telah disediakan dan data akan otomatis terkirim ke dalam database. Setelah mengirim data tersebut, maka user dapat menunggu proses penyeleksian berkas-berkas. Jika disetujui maka user atau calon pebghuni dapat melanjutkan ke proses berikutnya yaitu interview. Kemudian setelah interview, calon penghuni dapat melakukan pembayaran di Dinas 
Pengelolaan Bangunan dan Tanah Pemerintah Kota Surabaya, menandatangani surat perjanjian sewa menyewa dan mengambil kunci ruangan di UPTD Rumah Susun Penjaringan Sari Surabaya.

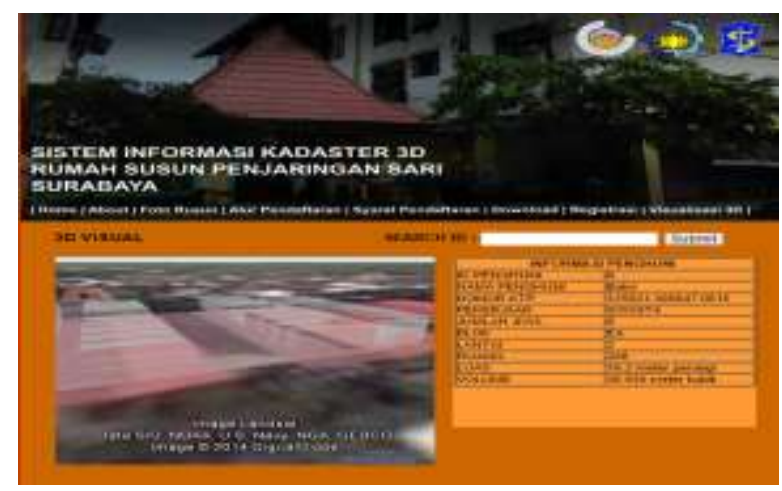

Gambar 25. Tamilan Halaman Visualisasi 3D

Halaman Visualisasi merupakan halaman yang dibuat dengan tujuan untuk menampilkan informasi rumah susun Penjaringan Sari dalam bentuk 3D dengan menggunakan ekstensi Google Earth API. Selain menampilkan gedung 3D, halaman ini dapat menampilkan informasi penghuni yang tinggal di dalam satuan rumah susun Penjaingan Sari Surabaya dalam bentuk form yang dapat dilihat oleh user sehingga user dapat melihat informasi letak ruang secara 3D beserta informasinya.

\section{PENUTUP}

\section{Kesimpulan}

Berdasarkan hasil penelitian di atas, dapat disimpulkan sebagai berikut:

1. Penelitian ini berhasil membuat model 3D dengan tipe solid dengan menggunakan fitur tool extrusion yang dimiliki oleh AutoCAD Civil 3D 2012 Metric. Hasil pemodelan 3D berupa bangunan rumah susun Penjaringan Sari Surabaya Blok EA dan EB dengan sistem koordinat UTM (Universe Transvere Mercator) dengan zona $49 \mathrm{~S}$.

2. Penelitian ini berhasil membuat desain basis data 3D dengan menggunakan perancangan model konseptual, model logikal, model fiskal dan mengimplementasikannya dengan menggunakan software PostgreSQL+PostGIS yang dapat menggabungkan data atribut dengan data spasial.

3. Penelitian ini berhasil mengintegrasikan basis data 3D dengan web sistem informasi kadaster
3D untuk membuat purwarupa sistem informasi kadaster 3D berbasis web sehingga dapat dijadikan bahan pertimbangan dalam membuat sistem yang dapat digunakan oleh khalayak umum dan instansi pemerintah demi meningkatkan layanan kepada masyarakat khususnya dalam bidang kadaster 3D.

\section{DAFTAR PUSTAKA}

Stoter, J.E. 2004. 3D Cadastre. Departement of Geodesy, Faculty of Civil Engineering \& Geosciences, Technical University Delft. Delft.

Undang-Undang Nomor 20 Tahun 2011. Rumah Susun.

Peraturan Walikota Nomor 30 Tahun 2013. Pelayanan di Bidang Pemakaian Rumah Susun.

Yudono, Adipandang. 2011. Sistem Informasi Pertanahan dan Aspek Operasional Pengelolaan Lahan Perkotaan. Universitas Brawijaya. Malang. 